\title{
Blood eosinophils and C-reactive protein as prognostic factors in severe chronic obstructive pulmonary disease exacerbations
} Hamed A. Hafiz, Heba Moussa

\begin{abstract}
Background Chronic obstructive pulmonary disease (COPD) is a leading cause of morbidity and mortality worldwide. Exacerbations of COPD are heterogeneous and have significant effect on the socioeconomic burden. The value of eosinophils (Eos) in predicting response to corticosteroids is documented in bronchial asthma exacerbation, but this value is not clear in COPD exacerbation. The aim of the study is to assess the prognostic value of blood Eos and C-reactive protein (CRP) in severe COPD exacerbations.
\end{abstract}

Patients and methods A total of 120 patients with COPD with severe exacerbations were subjected to complete blood count picture analysis with differential count, including Eos and CRP. Cases were divided into eosinophilic and nonesinophilic groups using $2 \%$ as a threshold, and the outcomes were observed.

Results The inpatient mortality rate was $10 \%$, and it significantly correlated with noneosinophilic group $(\leq 2 \%)$ $(P=0.02)$. The length of stay in hospital and ICU was significantly lower in patients with eosinophilia more than or equal to $2 \%$, with $P$ value less than 0.001 for both. CRP and

\section{Introduction}

Chronic obstructive pulmonary disease (COPD) is a main cause of morbidity and mortality in the world. It is expected to be in the third rank of causes of mortality by 2020 [1]. Exacerbations of COPD are heterogeneous. Several plasma markers are investigated to define phenotype of exacerbation and to predict outcome [2]. Blood eosinophils (Eos) were investigated as one of these markers. The role of Eos in pathogenesis of COPD is not clear and is still an area of debate [3]. The use of blood Eos as a marker of COPD exacerbation was first mentioned in 2011 [4] and has been confirmed in another study [5].

C-reactive protein (CRP) as a marker of systemic inflammation is elevated in COPD exacerbations. Elevated CRP is associated with worse outcome in COPD [6].

Exacerbations of COPD will markedly increase the socioeconomic burden of COPD [7]. Most cases with severe COPD exacerbations are managed with systemic steroids and antibiotics [8]. The value of Eos in predicting response to corticosteroids is documented in bronchial asthma exacerbation [9]. However, this value is not clear in COPD exacerbation. length of stay in hospital and ICU showed significant positive correlation.

Conclusion Higher blood Eos and lower CRP levels can be used as predictors for better outcome in severe COPD exacerbations.

Egypt J Bronchol 2019 13:605-609

( 2020 Egyptian Journal of Bronchology

Egyptian Journal of Bronchology 2019 13:605-609

Keywords: blood eosinophils, chronic obstructive pulmonary disease exacerbation, C-reactive protein

Department of Chest Diseases, Faculty of Medicine, Cairo University, Giza, Egypt

Correspondence to Hamed A. Hafiz, MD, Department of Chest Diseases, Faculty of Medicine, Cairo University, Giza, 11562, Egypt.

Tel: +201001649587

e-mail: hamed-md@hotmail.com

Received: 3 May 2019 Accepted: 9 July 2019

Published: 21 January 2020

The purpose of this study is to assess the prognostic value of blood Eos and CRP in severe COPD exacerbations.

\section{Patients and methods}

A prospective cross-sectional study was conducted on 120 patients with COPD with severe exacerbation in Kasr Al-Aini Hospital, Chest Department, Cairo University, in the period between March 2017 and March 2019. Diagnosis of COPD depends on triad of presence of symptoms, exposure to noxious stimuli, and preexacerbation spirometry in patient file with postbronchodilator forced expiratory volume in first second over forced vital capacity less than 0.70 [8]. The diagnosis of exacerbation depends mainly on the clinical features of the patient complaining of sudden worsening of condition that is more than usual day-to-day variability [8]. Written consent was obtained from all patients after approval of ethical committee of scientific research.

This is an open access journal, and articles are distributed under the terms of the Creative Commons Attribution-NonCommercial-ShareAlike 4.0 License, which allows others to remix, tweak, and build upon the work non-commercially, as long as appropriate credit is given and the new creations are licensed under the identical terms. 
All cases are considered to have severe exacerbation as they were admitted to either ICU or ward according to GOLD criteria. Indicators of severe exacerbation include severe symptoms such as sudden deterioration of resting dyspnea, worsening of oxygen saturation, and altered mental state. Acute respiratory failure, cyanosis, peripheral edema, and poor response to initial treatment of exacerbation are other indicators of severe exacerbation [8]. Patients were subjected to detailed history and clinical assessment, routine complete blood picture with differential count, CRP as a marker of inflammation, and arterial blood gases (ABGs). Consent was taken from all patients. We divided cases into eosinophilic and nonesinophilic groups using $2 \%$ as a threshold.

Exclusion criteria were patients with chronic comorbidities (e.g. heart failure, liver cell failure, renal failure, and malignancy), which may affect outcome, previous complete blood count with eosinophilia, and patients refusing to participate in the study.

All the patients had received the standard management of COPD exacerbation in the form of systemic steroids, antibiotics, and nebulized bronchodilators. Respiratory support in the form of oxygen therapy or ventilatory support was applied for indicated cases.

After that, the outcomes of the patients regarding duration of hospital stay, mechanical ventilation (MV) either invasive or noninvasive, and mortality were observed.

\section{Statistical methods}

Continues data were represented as mean and SD, and categorical data as number and percentage. The data were checked for normality using Shapiro-Wilk test. Comparison between two continuous groups was done using Mann-Whitney test, and between two categorical group was done using Fisher exact test. Linear correlation was done using Pearson correlation coefficient test. All tests were two sided. $P$ was considered significant if less than 0.05 . The statistical analysis was done using Minitab 17.1.0.0 for Windows (Minitab Inc., State College, Pennsylvania, USA).

\section{Results}

The demographic data of patients are summarized in Table 1. The prevalence of eosinophilia more than or equal to $2 \%$ in patients with COPD exacerbation was $39.17 \%$. The inpatient mortality rate was $10 \%$, and it is significantly correlated with noneosinophilic group $(\leq 2 \%) \quad(P=0.02$; Table 2$)$. Approximately $27.5 \%$ of
Table 1 Patient characteristics

\begin{tabular}{lcc}
\hline Variables & Mean & SD \\
\hline Age (years) & 52.58 & 5.29 \\
Eos\% & 2.37 & 2.39 \\
CRP (mg/l) & 120.53 & 54.95 \\
LOS in hospital (days) & 14.39 & 6.31 \\
LOS in ICU (days) & 12.11 & 5.91 \\
FEV $\%$ & 51.217 & 10.701 \\
FVC\% & 84.119 & 1.597 \\
FEV $/$ FVC\% & 57.95 & 4.928 \\
MV need (yes) & \multicolumn{3}{c}{$33(27.5)$} \\
One-month mortality (yes) & $12(10)$ \\
\hline
\end{tabular}

Continuous data were represented as mean (SD), and categorical data as $n(\%)(N=120)$. CRP, C-reactive protein; Eos, eosinophil; $\mathrm{FEV}_{1}$, forced expiratory volume in first second; $F E V_{1} / F V C$, forced expiratory volume in first second over forced vital capacity; FVC, forced vital capacity; LOS, length of stay; MV, mechanical ventilation.

Table 2 Patient outcomes in correlation with their eosinophil level

\begin{tabular}{lccc}
\hline Variables & $\begin{array}{c}\text { Eos } \geq 2 \% \\
(n=47)\end{array}$ & $\begin{array}{c}\text { Eos }<2 \% \\
(n=73)\end{array}$ & $P$ \\
\hline $\begin{array}{l}\text { LOS in hospital } \\
\text { (days) }\end{array}$ & $8(7-9)$ & $17(15-21)$ & $<0.001^{\mathrm{a}}$ \\
LOS in ICU (days) & $6(5-7)$ & $15(13-19)$ & $<0.001^{\mathrm{a}}$ \\
MV need (yes) & $10(21.28)$ & $23(31.51)$ & 0.2 \\
Mortality (yes) & $1(2.13)$ & $11(15.07)$ & $0.02^{\#}$ \\
\hline
\end{tabular}

Continuous data were represented as median and (IQR), and categorical data as $n(\%)(N=120)$. Eos, eosinophil; LOS, length of stay; MV, mechanical ventilation. ${ }^{a}$ Mann-Whitney test. ${ }^{\#}$ Fisher exact test, $P<0.05$, significant.

patients needed MV support within the treatment course, and their mean Eos\% was 1.67\%, which was significantly lower than the patients who were not in need of MV support (mean Eos\%=2.6\%) $(P=0.03$; Fig. 1). The length of stay (LOS) in hospital and ICU was significantly lower in patients with eosinophilia more than or equal to $2 \%$ ( $P<0.001$ for both; Table 2$)$. The linear relationship between Eos\% and LOS in hospital and ICU showed significant negative correlation $(r=-0.6$, $P<0.001$ and $r=-0.7, P<0.001$, respectively; Fig. 2). In contrast with Eos\%, the linear relationship between CRP and LOS in hospital and ICU showed significant positive correlation ( $r=0.4, P<0.001$ and $r=-0.3, P<0.001$, respectively; Fig. 3).

Furthermore, the bronchial obstruction level of patients (first second of forced expiration\%) showed negative correlation with length of hospital and ICU stay, and this correlation was not statistically significant (Table 3).

\section{Discussion}

COPD exacerbation has a significant effect on disease course. It worsens the quality of life $[10,11]$, symptoms, 

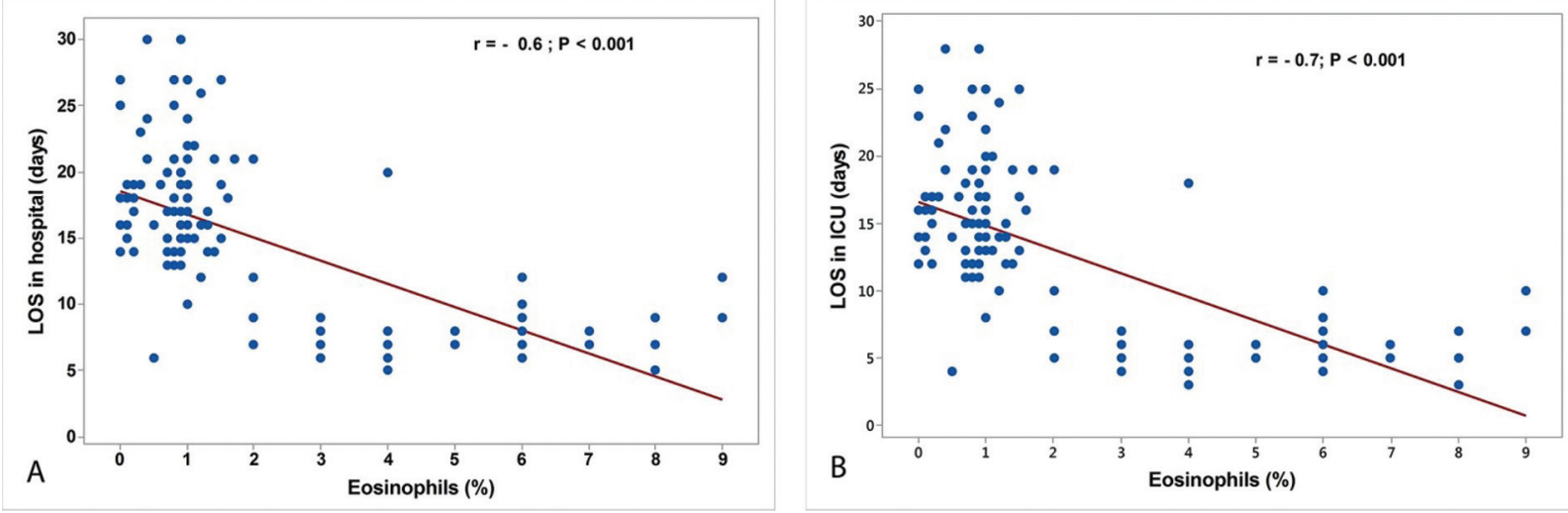

Eos\% level in correlation with MV support need. *Mann-Whitney test, $P<0.05$ considered significant. Eos, eosinophils; MV, mechanical ventilation.

Figure 2
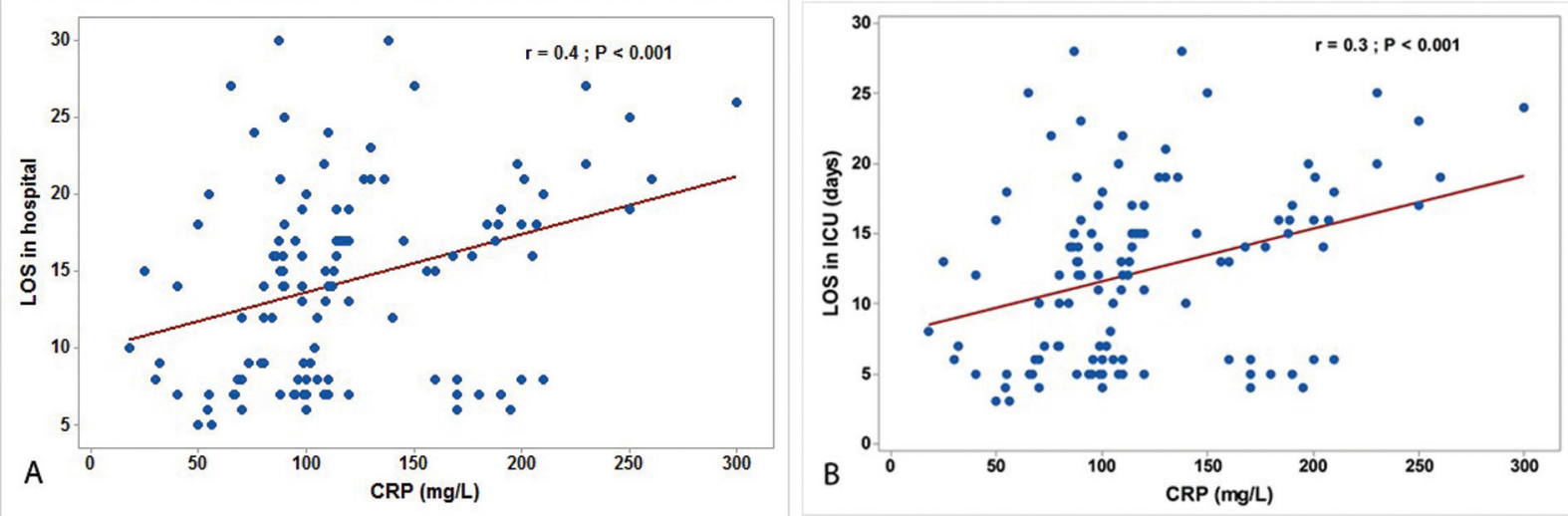

(a) Correlation of Eos\% level with LOS in hospital. (b) Correlation of Eos\% level with LOS in ICU. ${ }^{*}$ Correlation coefficient, $P<0.05$ considered significant, signs before $r$ denote the direction of relationship. Eos, eosinophils; LOS, length of stay.

Figure 3

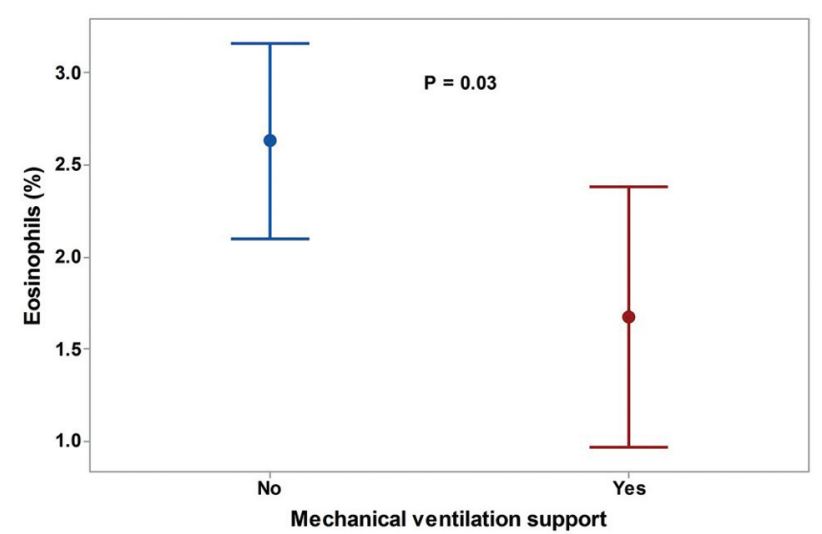

(a) Correlation of CRP with LOS in hospital. (b) Correlation of Eos\% level with LOS in ICU. *Correlation coefficient, $P<0.05$ considered significant, signs before $r$ denote the direction of relationship. CRP, Creactive protein; Eos, eosinophils; LOS, length of stay.

and pulmonary function [12]. It is also associated with more rapid deterioration of lung function $[13,14]$,
Table 3 Bronchial obstruction level in correlation with patient outcome

\begin{tabular}{lcc}
\hline Variables & \multicolumn{2}{c}{$\mathrm{FEV}_{1} \%$} \\
\cline { 2 - 3 } & $r$ & $P^{*}$ \\
\hline LOS in hospital (days) & -0.2 & 0.21 \\
LOS in ICU (days) & -0.18 & 0.2 \\
\hline
\end{tabular}

$\mathrm{FEV}_{1}$, forced expiratory volume in first second; LOS, length of stay. ${ }^{* *}$ Correspondence to Correlation coefficient, $P<0.05$ considered significant; signs before $r$ denote the direction of relationship.

significant mortality, and higher socioeconomic burden [15].

Our results showed that inpatient mortality was $10 \%$. Previous studies showed wide range of mortality rate from 2.5 to $24.5 \%$ [16-18]. This difference may be owing to different target population, quality of healthcare service, variable severity of exacerbation at time of admission, and associated comorbidities [19]. 
The relatively high mortality in this study may reflect that more severe cases were admitted to our department.

These results showed presence of blood Eos more than $2 \%$ in $39.17 \%$ of cases with severe exacerbation. This was higher than a recent study by Zeiger et al. [20] which had an incidence of $19 \%$. This difference may be owing to their utilization of a different threshold for eosinophilia.

Our results showed better outcome in eosinophilic group, regarding length of hospital and ICU stay, need for MV either invasive or noninvasive, and mortality (Table 2). This is consistent with a study by Villalobos et al. [21], who concluded that patients with eosinophilic exacerbation had shorter hospital stay and lower need for MV than noneosinophilic group. This study showed no significant difference in mortality in contrast to this study. This difference may be related to duration of follow-up for mortality, which was 1-year mortality in this study compared with inpatient mortality in this study. In another study, length of hospital stay is significantly shorter in eosinophilic exacerbations [22], whereas a retrospective study in ICU revealed that eosinophilic exacerbations had lower mortality in MV patients with COPD [23]. The better outcome may be related to better response to systemic steroids in eosinophilic group [24].Elevated CRP in this study is associated with longer hospital and ICU stay, denoting worse outcome. This is compatible with a recent study by Pahuja et al. [25] which concluded that elevated CRP is associated with poorer outcome in COPD exacerbation.

The main limitation of this study is the eosinophilic cutoff value, which varies in different studies. However, several studies used $2 \%$ as a cutoff value [21-24]. Further studies are needed to set a standard cutoff value. Other limitation is the duration of follow-up that was only during hospital admission with no longterm follow-up of exacerbation and mortality.

\section{Conclusion}

Higher blood Eos and lower CRP levels can be used as predictors for better outcome in severe COPD exacerbations.

\section{Financial support and sponsorship}

Nil.

\section{Conflicts of interest}

There are no conflicts of interest.

\section{References}

1 Eisner MD, Anthonisen N, Coultas D, Kuenzli N, Perez-Padilla R, Postma $D$, et al. An official American Thoracic Society public policy statement: novel risk factors and the global burden of chronic obstructive pulmonary disease. Am J Respir Crit Care Med 2010; 182:693-718.

2 Hurst JR, Donaldson GC, Perera WR, Wilkinson TM, Bilello JA, Hagan $\mathrm{GW}$, et al. Use of plasma biomarkers at exacerbation of chronic obstructive pulmonary disease. Am J Respir Crit Care Med 2006; 174:867-874.

3 Bafadhel M, Pavord ID, Russell REK. Eosinophils in COPD: Just another biomarker? Lancet Respir Med 2017; 5:747-759.

4 Bafadhel M, McKenna S, Terry S, Mistry V, Reid C, Haldar P, et al. Acute exacerbations of chronic obstructive pulmonary disease: Identification of biologic clusters and their biomarkers. Am J Respir Crit Care Med 2011; 184:662-671.

5 Gao P, Zhang J, He X, Hao Y, Wang K, Gibson PG. Sputum inflammatory cell-based classification of patients with acute exacerbation of chronic obstructive pulmonary disease. PLoS One 2013; 8:e57678.

6 Dahl M, Vestbo J, Lange P, Bojesen SE, Tybjaerg-Hansen A, Nordestgaard BG. C-reactive protein as a predictor of prognosis in chronic obstructive pulmonary disease. Am J Respir Crit Care Med 2007; 175:250-255.

7 O'Reilly JF, Williams AE, Rice L. Health status impairment and costs associated with COPD exacerbation managed in hospital. Int J Clin Pract 2007; 61:1112-1120.

8 From the Global Strategy for the Diagnosis. Management and Prevention of COPD, Global Initiative for Chronic Obstructive Lung Disease (GOLD) 2017. Available at: http://goldcopd.org. [Accessed 15 June 2018].

9 Green RH, Brightling CE, McKenna S, Hargadon B, Parker D, Bradding P, et al. Asthma exacerbations and sputum eosinophil counts: a randomised controlled trial. Lancet 2002; 360:1715-1721.

10 Kessler R, Stahl E, Vogelmeier C, Haughney J, Trudeau E, Lofdahl CG, et al. Patient understanding, detection, and experience of COPD exacerbations: an observational, interview-based study. Chest 2006; 130:133-142.

11 Spencer S, Calverley PM, Burge PS, Jones PW. Impact of preventing exacerbations on deterioration of health status in COPD. Eur Respir $J$ 2004; 23:698-702.

12 Seemungal TA, Donaldson GC, Bhowmik A, Jeffries DJ, Wedzicha JA. Time course and recovery of exacerbations in patients with chronic obstructive pulmonary disease. Am J Respir Crit Care Med 2000; 161:1608-1613.

13 Donaldson GC, Seemungal TA, Bhowmik A, Wedzicha JA. Relationship between exacerbation frequency and lung function decline in chronic obstructive pulmonary disease. Thorax 2002; 57:847-852.

14 Kanner RE, Anthonisen NR, Connett JE. Lower respiratory illnesses promote $\mathrm{FEV}_{1}$ decline in current smokers but not ex-smokers with mild chronic obstructive pulmonary disease: results from the Lung Health Study. Am J Respir Crit Care Med 2001; 164:358-364.

15 Wouters EF. The burden of COPD in The Netherlands: results from the Confronting COPD survey. Respir Med 2003; 97:S51-S59.

16 Patil SP, Krishnan JA, Lechtzin N, Diette GB. In-hospital mortality following acute exacerbations of chronic obstructive pulmonary disease. Arch Intern Med 2003; 163:1180-1186.

17 Hartl S, Lopez-Campos JL, Pozo-Rodriguez F, Castro-Acosta A, Studnicka M, Kaiser B, et al. Risk of death and readmission of hospital-admitted COPD exacerbations: European COPD Audit. Eur Respir J 2016; 47:113-121.

18 Steer J, Norman EM, Afolabi OA, Gibson GJ, Bourke SC. Dyspnoea severity and pneumonia as predictors of in-hospital mortality and early readmission in acute exacerbations of COPD. Thorax 2012; 67:117-121.

19 Roberts CM, Barnes S, Lowe D, Pearson MG. Evidence for a link between mortality in acute COPD and hospital type and resources. Thorax 2003; 58:947-949.

20 Zeiger RS, Tran TN, Butler RK, Schatz M, Li Q, Khatry DB, et al. Relationship of blood eosinophil count to exacerbations in chronic obstructive pulmonary disease. J Allergy Clin Immunol Pract 2018; 6:944-954.

21 Villalobos R, Magallanes J, David-Wang A. P143 Blood eosinophilia as predictor for patient outcomes in COPD exacerbations: a systematic review and meta-analysis. Thorax 2016; 71:A160.

22 Bafadhel M, Greening NJ, Harvey-Dunstan TC, Williams JE, Morgan MD, Brightling $\mathrm{CE}$, et al. Blood eosinophils and outcomes in severe hospitalized exacerbations of COPD. Chest 2016; 150:320-328 
23 Salturk C, Karakurt Z, Adiguzel N, Kargin F, Sari R, Celik ME, et al. Does eosinophilic COPD exacerbation have a better patient outcome than noneosinophilic in the intensive care unit? Int $J$ Chron Obstruct Pulmon Dis 2015; 10:1837-1846.

24 Bafadhel M, McKenna S, Terry S, Mistry V, Pancholi M, Venge P, et al. Blood eosinophils to direct corticosteroid treatment of exacerbations of chronic obstructive pulmonary disease: a randomized placebo-controlled trial. Am J Respir Crit Care Med 2012; 186:48-55.

25 Pahuja S, Yadav P, Gautam AK, Kumar A, Kumar A, Chaudhri S. Study of serum C-reactive protein levels in acute exacerbations of chronic obstructive pulmonary disease patients. Int J Med Sci Public Health 2016; 5:694-699. 